\title{
Onnauwkeurig maar beter
}

Economische voorspellingen zijn nogal eens mis, maar dat mag toch geen reden zijn ermee op te houden. Zo ver er naast zijn zij nu ook weer niet. Het komt er op aan na te gaan in welk opzicht zij te kort schieten om een oordeel over voorspelprestaties te vellen. Wij vinden dan bijvoorbeeld met betrekking tot de voorspellingen van het CPB dat loon- en prijsveranderingen beter worden voorspeld dan het saldo op de lopende rekening van de betalingsbalans - een klein verschil tussen twee grote bedragen -, dat het optreden van versnellingen en vertragingen beter wordt voorspeld dan de grootte ervan en dat jaarprognoses beter zijn dan die op middellange termijn (Driehuis 1977; Elte 1978).

Paul Samuelson heeft de ervaringen die wij met macro-economische voorspellingen opdoen, eens samengevat in tien lessen - dat zei hij, maar het waren er elf - van gemiddeld één minuut. Voor een methodoloog zijn de interessantste (Samuelson 1974):

'Lesson 1. Economists cannot forecast the future with precision.

Lesson 2. Neither can anyone else, and the forecasts made by professional economists are systematically better than any made by brokers, bankers or business men.

Lesson 11. ... economics remains an art rather than a science.'

Hoe komt het dat economen niet precies, maar wel beter voorspellen dan niet-economen en waarom zijn zij zulke artiesten? Bij het zoeken naar een antwoord op die vraag zal ik zoals Samuelson alleen hun macro-economische voorspellingen beschouwen. Die vallen het meest in het oog en door de beperking kunnen enkele complicaties worden vermeden waarvoor nu geen ruimte is.

\section{Verwachtingspatronen}

Wat het meest bij economen opvalt, is dat zij over theorieën beschikken. Zij proberen daarmee gebeurtenissen (feiten, verschijnselen) te verklaren. Als wij denkbare gebeurtenissen in een domein met gebruikmaking van een aantal algemene uitspraken, nl. hypothesen, hebben geordend in mogelijke en onmogelijke configuraties van gebeurtenissen, hebben wij een theorie en kunnen wij ze voorwaardelijk voorspellen. De theorie zegt dan bijv:

'Onder voorwaarde $X$ zal, als een gebeurtenis uit de verzameling van 
gebeurtenissen $Y$ plaatsvindt, altijd een gebeurtenis uit $Z$ plaatsvinden,' of kort genoteerd: $X \rightarrow(Y \rightarrow Z)$. Volgens deze theorie is de configuratie: $X$ en $Y$ zonder $Z$ niet en zijn alle andere configuraties met of zonder $X, Y$ en $Z$ wel mogelijk.

Een theorie is een verwachtingspatroon. Als zich een concreet geval $x_{i}$ voordoet $\left(x_{i} \varepsilon X\right)$ en tevens een concrete gebeurtenis $y_{\imath}$ plaatsvindt $\left(y_{i} \varepsilon Y\right)$, dan kunnen wij voorspellen dat de concrete gebeurtenis $z_{t}$ zal plaatsvinden $\left(z_{i} \varepsilon Z\right)$. De uitspraak $x_{t} \rightarrow\left(y_{t} \rightarrow z_{i}\right)$, die een voorspelling weergeeft, is een deelverzameling, nl. een instantie van de algemene theorie: $X \rightarrow(Y \rightarrow Z)$. De mogelijke configuratie van gebeurtenissen: $x_{i} y_{i} z_{i}$, lag al vast in het verwachtingspatroon. Door $x_{i}$ en $y_{i}$ (de initiële voorwaarde) in de automaat van de theorie te stoppen kwam de enig mogelijke configuratie van $x_{i}$ en $y_{i}$, nl. met $z_{\imath}$ (de voorspelling) eruit.

Hiermee zijn wij echter, hoe fraai ook op papier, nog niet veel opgeschoten, want ook niet-economen die voorspellen, hebben kennelijk verwachtingspatronen. Het moge bij hen wat minder opvallen, zij hebben ook zo hun theorieën. Wie geregeld naar de televisie kijkt, de krant leest, naar ministers luistert en praat met zijn medeburgers, met inbegrip van makelaars, bankiers en zakenlui, kan zich een aardig overzicht ervan vormen. Er blijken dan evenmin als onder de economen veel uiteenlopende theorieën te bestaan, want in onze wereld waarin de dialoog in ere wordt gehouden, praat nu eenmaal de een de ander graag en met grote toewijding na. Omdat economen, wat er ook van ze mag worden gezegd, veel vertrouwen wekken, zijn de theorieën van de niet-economen bovendien in de regel niet meer dan slordige versies van professionele verwachtingspatronen.

De betere kwaliteit van de voorspellingen der economen schijnt dan ook het gevolg te zijn van de minder nonchalante manier waarop zij met hun denkbeelden omgaan. Ook al wordt er wel eens aan getwijfeld of zij ware wetenschappers zijn, hun betere voorspellingen zijn het bewijs ervan dat zij niet helemaal vergeefs het empirisch-wetenschappelijke ideaal nastreven. $\mathrm{Zij}$ nemen het wat nauwer met de formele eisen waaraan theorieën die verklaren en voorspellen, moeten voldoen; zij besluiten niet te lichtvaardig over de aanvaarding of verwerping ervan en zij zijn talentvoller en geoefender in de kunst van het weloverwogen en goed aanvoelend gissen. Zij zijn echter niet in staat het empirisch-wetenschappelijke ideaal zo verregaand te verwezenlijken als dat in een 'harde' wetenschap als bijv. de natuurkunde het geval blijkt te zijn. Dat verklaart dan waarom economen ondanks hun goede bedoelingen wel eens verkeerd, althans nogal onnauwkeurig, voorspellen.

\section{Contradictoire en tautologische niet-voorspellingen}

Wie voorspelt dat de lopende rekening van de betalingsbalans in 1982 een overschot en een tekort vertoont, zegt iets wat nooit waar kan zijn en voorspelt dus niets. Wie voorspelt dat er in dat jaar een overschot of geen overschot zal zijn, zegt iets wat altijd waar is en voorspelt dus evenmin iets. Contradictoire en tautologische niet-voorspellingen doen het soms goed in de politiek, maar niet in de wetenschap. 
De voorspellingen die een empirisch-wetenschappelijke theorie oplevert zijn altijd contingente uitspraken: zij zijn waar of niet waar. Zij kunnen daarom met andere contingente beweringen in strijd zijn. De contingente uitspraak dat er in 1982 een overschot is, wordt door de contingente uitspraak dat er een tekort is, weersproken. Theorieën waarmee kan worden voorspeld, moeten kunnen worden tegengesproken.

De voorsprong van de economen op de leken schijnt voor een belangrijk deel erin te bestaan dat hun verwachtingspatronen consistenter zijn en beter volgens de logische regels door hen worden gehanteerd, zodat zij zich minder aan contradicties schuldig maken. Zij hebben zich de afgelopen tweehonderd jaar dan ook druk bezig gehouden met het analyseren en hebben het daarin ver gebracht. $\mathrm{Zij}$ doen praktisch geen contradictoire niet-voorspellingen. Zij spreken integendeel nogal eens een vermanend woord tot niet-economen door hen bijvoorbeeld erop te wijzen dat een opgegeten koek niet kan worden aangesneden, dat door devaluatie de invoerprijzen niet worden verlaagd en dat het verband tussen het financieringstekort van de overheid en de kapitaalmarktrente niet kan worden vastgesteld zonder daarbij het financieringstekort van het bedrijfsleven te betrekken. Behalve verrassende uitspraken bevat de wetenschap, zoals Kenneth Boulding heeft opgemerkt, heel wat empirische waarheden als koeien, zoals in de economie de wet van de afnemende meeropbrengsten (Boulding 1981). De begrippensystemen en ideeënwereld van economen en niet-economen overlappen elkaar voldoende om soms met vrucht te kunnen wijzen op verkeerde redeneringen.

Op het gebied van de tautologie is het gedrag van de economen wat minder voorbeeldig. $\mathrm{Zij}$ tellen zelfs enkele meesters in het tautologisch niet-voorspellen. Tautologieën hebben op deze filosofen, want zo mogen wij hen wel noemen, de uitwerking van een koplamp op een konijn. Als bijvoorbeeld Ludwig von Mises of Fritz Machlup de hypothese van het rationele handelen zo geformuleerd wensen te zien dat die niet kan worden weersproken, openen zij wellicht enkelen de ogen om roerloos en gefascineerd door onomstotelijke waarheid de 'zin' van het economisch handelen te beseffen, zij leveren daarmee geen bijdrage tot een theorie waarmee kan worden voorspeld (Klant 1978). Tautologieën zijn nuttige analyseerinstrumenten, zoals iedere accountant weet, maar ze zijn te zwaar belast met zekerheid om de risico's te kunnen dragen die iedere voorspeller op zich neemt als hij gebeurtenissen aankondigt die wel eens zouden kunnen uitblijven. Voorspellers zijn ondernemers.

\section{Metafysische niet-voorspellingen}

Behalve aan de syntactische eis van contingentie moet een theorie waarmee wordt voorspeld, aan een semantische eis voldoen. Het moet mogelijk zijn door de invoering van initiële voorwaarden die betrekking hebben op waarneembare gebeurtenissen, conclusies te trekken omtrent gebeurtenissen die eveneens kunnen worden waargenomen. De theorie moet daartoe een aantal operationeel - d.i. in termen van meetoperaties of observaties - definieerbare begrippen bevatten. Dit levert de nodige problemen op voor wie er 
bijvoorbeeld hypothesen over 'permanent inkomen' of denkbeelden over de oplossing van 'het transformatieprobleem' op nahoudt. Hoe nemen wij toekomstig inkomen of de transformatie van 'gestolde arbeid' in prijzen waar?

Operationeel definiëren is overigens niet voldoende, want wat hebben wij eraan als wij de meetoperaties wel kunnen omschrijven, maar niet goed uitvoeren? De schatting van ons nationale inkomen bijvoorbeeld is door de vermoedelijk toenemende activiteit van in grote getale frauderende burgers van de Nederlandse rechtsstaat waarschijnlijk nogal onnauwkeurig en de informatie die de staatsboekhouding verschaft omtrent het financieringstekort van de overheid, laat blijkbaar ook wel eens wat te wensen over. Niettemin drukken wij het tekort uit in tienden van percenten van het nationale inkomen en stellen wij, met eerbied door de natie aangehoord, vast dat het 'structurele bestanddeel' ervan is gestegen. Wij hebben dan echter niet met een feit te doen, maar met een uitspraak van vooraanstaande en oprechte landgenoten wier overtuigingskracht niet berust op betrouwbare meetoperaties, maar op een indrukwekkend taalgebruik.

Cijfers zijn nog geen feiten. In de afgelopen tien jaren was het jaarlijkse saldo van de niet-monetaire sectoren op de Nederlandse betalingsbalans op kasbasis systematisch - nl. gemiddeld $30 \%$ - lager dan volgens de (vermoedelijk op dit punt nauwkeuriger) monetaire analyse van de Nederlandsche Bank. Het lagere cijfer pleegt te worden gebruikt om het land bij tijd en wijle de schrik op het lijf te jagen en het hogere om op rustige wijze de geldschepping te beoordelen. De geldtheorie en de betalingsbalanstheorie bevatten beide begrippen die operationeel definieerbaar zijn, maar de pogingen om de operaties uit te voeren zijn soms nogal gebrekkig. Voorspellingen omtrent het saldo op de lopende rekening zijn meestal verkeerd, maar als er een uitkomt, is misschien wel niet een economisch, maar een rekenkundig feit goed voorspeld, nl. de uitkomst van een verkeerde schatting.

Er is daarom, als het op voorspellen aankomt, praktisch geen verschil tussen een hypothese die op niet-operationeel definieerbare begrippen berust en een hypothese die zich bedient van begrippen die zijn gedefinieerd in termen van meetoperaties die niet nauwkeurig genoeg kunnen worden uitgevoerd. In het eerste geval moet de theorie worden verbeterd en in het tweede de statistiek. Zo lang het ene en het andere niet zijn gelukt, zijn de in de theorie veronderstelde gebeurtenisen niet-waarneembaar. In beide gevallen levert de theorie dan metafysische niet-voorspellingen op. $\mathrm{Zij}$ vormen nogal eens de motivatie van beleid dat vastberaden en vol vertrouwen wordt uitgevoerd.

\section{Toetsen}

De vermelde syntactische en semantische eisen constitueren een noodzakelijke voorwaarde waaraan overeenkomstig het empirisch-wetenschappelijke ideaal een theorie waarmee wordt voorspeld, moet voldoen. De theorie mag niet contradictoir, tautologisch of metafysich niet-voorspellen. Uiteraard is een theorie die aan die eisen voldoet, daarmee nog geen goede 
theorie. Een theorie waarmee voorspellingen worden gedaan, moet ook voorspellingen leveren die in bevredigende mate uitkomen. Dat laatste kan niet worden vastgesteld door analyse van de theorie en van de methode volgens welke gebeurtenissen worden waargenomen. Het kan alleen maar proefondervindelijk, d.w.z. door de praktijk van het voorspellen zelf. Een theorie moet zichzelf in het gebruik bewijzen.

In de empirische wetenschap pleegt die bewijsvoering te worden geforceerd door de theorie niet lukraak in handen te geven van de gebruikers, maar door haar intersubjectief te toetsen, d.w.z. de voorspelkracht ervan te beproeven door het uitvoeren van geleide experimenten of - zoals veelal in wetenschappen als de astronomie, de astrofysica, de meteorologie of de economie - door systematische waarnemingen.

Hoewel het woord 'toetsen' vandaag veel door economen wordt gebruikt, bestaat hun tragiek erin dat zij - buiten hun schuld overigens - universele theorieën niet goed kunnen toetsen. Zij bepalen zich in feite meestal tot het schatten van simultane relaties, vaak zonder in een volledig onderzoekverslag intersubjectieve verantwoording af te leggen. $\mathrm{Zij}$ toetsen dan niet hypothesen, maar beroepen zich integendeel op hypothesen ter verzekering van de plausibiliteit van hun schattingen.

Toetsen dient om te beslissen over de verwerping of aanvaarding (nietverwerping) van theorieën of hypothesen. Het dient niet om de waarheid ervan te bewijzen. Universele contingente uitspraken kunnen nu eenmaal wel worden bevestigd maar niet geverifieerd. Wie de bij de logici geliefde zwanen beu is, probere het eens met ijsberen. Hij zal dan inzien dat iedere witte ijsbeer een bevestiging oplevert van de stelling dat ijsberen wit zijn, maar niet het bewijs dat alle nog waar te nemen ijsberen er zo uitzien. Eén instantie echter die niet wordt bevestigd, bijv. door de uitroep: 'Een bruine ijsbeer!', levert al een tegenspraak op met de universele theorie. De waarneming van het bruine beest zou de witte-ijsberentheorie kunnen doen wankelen. Een theorie kan logischerwijze wel worden gefalsifieerd, maar niet geverifieerd.

Eigenlijk gaat het bij het toetsen om nog minder, nl. alleen maar om de beslissing of wij de ene boven de andere theorie zullen verkiezen. Welke theorie voorspelt het beste? Als een theorie slecht voorspelt, maar er is geen betere rivaliserende theorie voorhanden, zal de theorie meestal niet worden afgeschaft. Er is dan uiteraard wel aanleiding om het onderzoek voort te zetten zodat ze althans in de toekomst zou kunnen worden verbeterd of vervangen. Soms is het vertrouwen in het succes van dat nadere onderzoek zelfs reden om een op dit ogenblik inferieure nieuwe theorie te verkiezen boven een oude die, naar men aanneemt, geen verdere vooruitzichten biedt. Ook de onderzoekers die aan voorspellers theorieën leveren, nemen risico's.

De oorzaak van de tragedie der economen schijnt erin te bestaan dat zij teneinde te voorzien in dringende maatschappelijke behoeften, de werking van zeer complexe systemen trachten te doorgronden zonder dat zij er tot dusver in slagen relevante universele numerieke constanten te vinden. De wereld van de sociale wetenschap is onderhevig aan veel snellere historische veranderingen dan die van de natuurwetenschap. De economen beschikken 
daardoor niet over zoiets als een universele gravitatieconstante, een invariante lichtsnelheid of de $h$ van Planck. Hun domein verandert dagelijks doordat de mens leert en onvoorspelbaar creëert. De economie is een historische wetenschap.

Het is echter onjuist te menen dat historici niet voorspellen. Zij doen het wel degelijk, net als de economen niet al te precies, maar in de regel wel beter dan de niet-historici. $\mathrm{Zij}$ voorspellen niet met de nauwkeurigheid die voor menig doel van de gebruikers wenselijk wordt geacht, maar zij doen evenals alle empirische onderzoekers algemene uitspraken die zij door onderzoek beproeven en waaruit conclusies kunnen worden getrokken omtrent nog niet waargenomen gebeurtenissen in het verleden en de toekomst. Een voorspelling was bijv. de inmiddels bevestigde uitspraak van Ernest Nagel in 1960 dat met grote waarschijnlijkheid de volgende president van de Verenigde Staten geen communist, geen neger en geen vrouw zou zijn (Nagel 1974). Een fysicus die zou moeten zeggen waar en wanneer zich een bepaald deeltje zal bevinden, zou niet meer kunnen vertellen. Een historicus is in staat uitspraken van deze soort te doen die in een complex en zorgvuldig verantwoord verwachtingspatroon zijn vastgelegd en die meer configuraties uitsluiten dan het simpele verwachtingspatroon van een niethistoricus als Nagel.

De historicus die echter met behulp van zijn algemene theorieën concrete gebeurtenissen met grotere precisie zou moeten voorspellen, bijv. wanneer het Warschau-pact zal worden ontbonden, zou zich daarmee op hetzelfde gladde ijs begeven als de macro-econoom die met behulp van zijn theorieën meent te kunnen voorspellen wanneer de opleving komt die aan de werkloosheid van vandaag een einde zal maken. De voorspelkracht van historische wetenschappen is beperkt als gevolg van onvoorzienbare 'structurele' veranderingen.

De historicus en de econoom die geen universele constante parameters kennen, zetten, als zij niettemin concrete gebeurtenissen trachten te voorspellen, hun algemene theorie - hun grondtheorie - om in een specifiek model, een stelsel van simultane relaties dat geen instantie ervan is. De initiële voorwaarden die zij dan invoeren om te voorspellen, berusten bovendien ten dele niet op waarnemingen, maar op gissingen. De voorspelling omtrent de afloop van het Warschau-pact zou zijn gebaseerd op de schatting van een groot aantal exogene variabelen. Die beschrijven gebeurtenissen die wel eens plaats zouden kunnen vinden. Het uitkomen van de voorspelling is afhankelijk van gebeurtenissen die zich eventueel kunnen voordoen.

\section{Grondtheorie en specifiek model}

Economische grondtheorieën zijn idealisaties. Zij berusten op verregaande abstractie en op veronderstellingen waaraan in werkelijkheid niet kan worden voldaan, zoals die van een gesloten economie met twee sectoren. De economen behoeven zich daarvoor in het geheel niet te schamen. $\mathrm{Zij}$ kunnen zich integendeel met gepaste zelfingenomenheid beroepen op de gezaghebbende uitspraak van Ernst Mach dat alle natuurkundige wetten en begrippen idealisaties zijn. Door een synthetische combinatie ervan kunnen con- 
crete gebeurtenissen, hoe gecompliceerd ook, worden gereconstrueerd (Mach 1906). Met behulp van andere idealisaties kan bijv. het gedrag van een lichaam worden verklaard dat niet valt zoals Galilei's idealisatie het wil. Doordat de wetten numerieke constanten bevatten, kan de resultante van gezamenlijk werkende krachten worden berekend.

Het is echter vervelend voor de theoretische economen dat zij veel meer dan de natuurkundigen problemen hebben in hun omgang met de dimensie 'tijd'. Hun theorieën zijn in de regel comparatief-statisch of als zij dynamisch zijn, zeer sterk gestileerd. Een voorbeeld is de volgende comparatiefstatische minitheorie, waarin voor het gemak lineariteit van de gedragsvergelijking is aangenomen:

$$
\begin{array}{ll}
Y=C+\bar{I} & \\
C=c Y & 0<c<1
\end{array}
$$

Deze theorie stelt in staat tot de uitspraak:

$$
d \bar{I} \rightarrow d Y=\frac{d \bar{I}}{1-c}>d \bar{I}
$$

$c$ is echter geen werkelijke constante, maar verschilt naar plaats en tijd. Als wij niet beschikken over een theorie waarmee veranderingen van $c$ kunnen worden voorspeld en met Samuelson aannemen dat $c$ vrij veranderlijk is (Samuelson 1940), dan volgt slechts uit de theorie:

$$
d \bar{I} \rightarrow d C, \quad d Y \frac{>}{<} 0
$$

De theorie levert dan tautologische niet-voorspellingen op. Economen die zich terugtrekken op zo'n oninneembaar bastion, hebben altijd gelijk, maar zij kunnen niet voorspellen.

Zo vrijblijvend plegen de macro-economen zich echter niet op te stellen. Zij nemen aan dat de structuurparameters 'stabiel' zijn, d.w.z. min of meer constant in de tijd (binnen een zekere periode). Wij kunnen dan trachten ze door statistische analyse naar plaats te schatten teneinde een econometrisch model te vormen met operationeel gedefinieerde grootheden en numerieke constanten. Het kan fungeren als een verwachtingspatroon waarmee voorspellingen worden gedaan voor een tijdruimtelijk bepaald domein, zoals de economie van Nederland in het komende jaar of de Belgische frisdrankenmarkt in de jaren 1980.

Zo'n specifiek model is dan echter geen instantie van de grondtheorie. De algemene theorie biedt daartoe aan de gebruikers te veel vrijheid om het verkeerd te doen. $\mathrm{Zij}$ hebben de keuze hoe zij de theoretische begrippen zullen operationaliseren. Zij kunnen desaggregaties toepassen en hulphypothesen inschakelen door de invoering van 'proxies'. Zij hebben ook de keuze van dynamisering d.w.z. hoe de tijd als variabele zal worden ingevoerd 
en hoe de variabelen zullen worden gedateerd en daarmee welke vertragingen zullen worden verondersteld. De wiskundige vorm wordt eveneens gekozen en het model wordt vaak vermeerderd met hypothesen die in de grondtheorie niet zijn opgenomen.

Een specifiek model is een interpretatie, waarbij uit meer dan één grondtheorie kan zijn gekozen. Omdat het geen instantie is, betekent tegenspraak van het model geen tegenspraak van de theorie. Als een Keynesiaans model slechter voorspelt dan een monetaristisch - wat overigens wegens beider gebreken niet gemakkelijk is aan te tonen - behoeft Friedman niet boven Keynes te worden verkozen, want de onderzoeker die Keynes' theorie plausibeler acht en meer in overeenstemming met de 'natuurlijke orde' die hij meent te kunnen ontwaren, verwerpt zijn interpretatie, maar niet zijn theorie. Hij zal zijn onderzoek voortzetten naar het beter voorspellende Keynesiaanse model. De veronderstelling van stabiele structuurparameters in een grondtheorie luidt: 'Er bestaat voor ieder gebied tenminste één specifiek model dat aan de theorie voldoet en goed voorspelt'. Dit is een zg. existentiële bewering. Existentiële uitspraken zijn niet-falsifieerbaar. Grondtheorieën zijn daarom heuristische systemen, waarover in laatste aanleg wordt besloten in een discussie over plausibiliteit. Zo lang er geen effectieve procedure bestaat om alle mogelijkheden af te tasten, kunnen zij niet worden getoetst.

Misschien vinden wij er eenmaal nog wat op. Er zijn vandaag econometristen die serieus werk maken van een betere methodologische onderbouwing van hun onderzoek (Leamer 1978; Sims 1980; Malinvaud 1981). Zij zouden ons in ieder geval dichter kunnen brengen bij een strenge bewijsvoering. Voorlopig is het echter nog zo dat degenen die geloven dat de vraag naar geld rente-elastisch is, hun hypothese plausibel blijven achten en met overtuiging toepassen bij de beoordeling van beleid, ook al blijkt uit de toepassing van moderne methoden van specificatie-onderzoek dat hun stelling door de statistische analyse niet wordt bevestigd (Cooley 1981). Economisch geloof is moeilijk te weerleggen. Beleid is gebaseerd op verwachtingspatronen waarmee wordt voorspeld, modelmatig of in de vorm van ferme praat. Als het mislukt, blijft altijd de mogelijkheid open om het falen te verklaren zonder de theorie aan te tasten. Misschien moet Engeland Thatcher. vrezen, maar Friedman heeft weinig van haar te duchten.

\section{Kunst en wetenschap}

De laatste les van Samuelson is slecht geformuleerd. Niet alleen de economie, maar iedere wetenschap berust immers op kunst - niet in de zin van 'techniek' of 'beleid', zoals in de negentiende eeuw werd bedoeld als men het had over 'political economy as an art'; maar in de zin van creatieve activiteit, die berust op goede ingevingen en fantasie en leidt tot verrassende ontdekkingen en veranderingen van ons beeld van de werkelijkheid. Ook de economen, die het gedrag van mensen trachten te verklaren, hebben hun invallen, ook al zullen die nooit zo fantastisch behoeven te zijn als die van Newton, Einstein of Planck. Zij kunnen dichter bij huis blijven. Door een beroep op empathie en directe ervaring maken zij de wereld begrijpe- 
lijker, wat je van natuurkundigen niet bepaald kunt zeggen.

Ook economen kunnen echter geen theorieën ontwerpen zonder verbeeldingskracht, zelfs niet als zij die door inductie uit de feiten menen te kunnen afleiden. Uit feiten kan niets worden afgeleid. Inductie berust eveneens op invallen, hypothesen en deducties. Wie iets meent te hebben geleerd van de feiten, heeft ze eerst op grond van denkbeelden geselecteerd, gerangschikt en in het licht van theorieën bekeken. Hij heeft ze gebruikt om nadere vermoedens op de proef te stellen. Het resultaat is dan een denkbeeld dat met empirisch bewijs kan worden gestaafd.

Van economen wordt evenwel veel meer artisticiteit dan van natuurkundigen verwacht, als het op voorspellen aankomt. Dat zal Samuelson wel hebben bedoeld. Als gevolg van de moeilijkheden van de toetsing, berust hun keuze van het specifieke model al ten dele op 'gevoel'. Met zo'n model valt bovendien niets te bereiken zonder nog meer kunst. De initiële voorwaarden die in het mechaniek moeten worden gestopt, liggen niet voor het oprapen. $\mathrm{Zij}$ hebben in de regel niet betrekking op waargenomen gebeurtenissen, maar op wat eerst kan worden waargenomen nadat de voorspelling al is gedaan. De voorspelling van een econoom is een rationele gok. Hij schat op grond van onvolledige informatie, gebrekkige inzichten, ervaring en vermoedens een aantal grootheden, waardoor de waarden van de endogene variabelen worden bepaald. Hij past daarbij ook een terugkoppeling toe. De uitkomsten worden op hun plausibiliteit beoordeeld en eventueel aangepast door herschatting van de exogene variabelen (Elte 1978). Alle uit een theorie afgeleide voorspellingen zijn voorwaardelijk, want er moet een concrete randvoorwaarde, d.w.z. een initiële voorwaarde, worden ingevoerd. Economische voorspellingen zijn echter dubbel voorwaardelijk of beter, zij berusten op een initiële voorwaarde en een niet-theoretisch voorbehoud. Het model kan goed zijn, maar de voorspeller fout.

De betere uitkomsten van deze paradoxale manier van voorspellen, vergeleken met die van de niet-econoom, hangen ook nu weer samen met de consistentie ervan. Het model sluit ook als het zeer complex is contradictoire en tautologische niet-voorspellingen uit. De verwachte gebeurtenissen vertonen een systematische plausibele samenhang. Aangezien echter het geheel afhankelijk blijft van minder streng gestructureerde gissingen en intuïties, blijft het mogelijk dat de uitspraken van voorspellers beïnvloed zijn door hun stemmingen, durf en verbeeldingskracht. Er zijn modelmatige voorspellers, die evenals makelaars, bankiers en zakenlui pessimisten of optimisten zijn. Ook modelmatige voorspellingen behoren te berusten op de 'common senses and practical instincts', die volgens Alfred Marshall iemand tot een betere econoom maken (Marshall 1961).

Omdat er gegist moet worden en wegens de wankelheid van de parameters, is het geen wonder dat jaarprognoses betrouwbaarder plegen te zijn dan voorspellingen op langere termijn. De toekomst van de mensheid is nu eenmaal onzekerder dan die van het heelal. De economie is een historische wetenschap. Het is daardoor ook mogelijk dat een economisch kunstenaar die concrete feiten kent en weet te schikken - kortom, goed aanvoelt wat er in de wereld gebeurt - de rekenaars soms overtreft. Omdat zijn speculaties onbewijsbaar zijn, doet hij het dan in de regel beter in zaken dan in de 
politiek. Hij is van slechte voorspellers moeilijk te onderscheiden. Zelfs Keynes heeft geen succes gehad, toen hij de Keynesianen in wording in 1937, toen de werkloosheid in Groot-Brittannië nog $11 \%$ was, waarschuwde voor de te verwachten inflatoire en recessieve gevolgen van voortgezette expansie van de overheidsbestedingen bij een gelijktijdige groei van het bedrijfsleven (Keynes 1937). Wie goed wil voorspellen in de economie, moet niet alleen goed kunnen rekenen, maar ook goed gissen. Wie succes wil hebben met zijn artistiek-wetenschappelijke prestaties, moet het liefst op korte termijn voorspellen en, als het om de langere termijn gaat, in aanzien staan en welsprekend zijn, zodat zijn speculaties worden geloofd. Helaas zijn de beide voorwaarden voor blijvend succes - goed gissen en overtuigen - vaak niet simultaan vervuld, als de economen en de nieteconomen elkaar ontmoeten.

\section{Literatuur}

K. E. Boulding, Evolutionary Ecomics, Beverley Hills, 1981, p. 11.

T. F. Cooley en S. F. Leroy, 'Identification and Estimation of Money Demand', American Economic Revieu, LXXI (1981), pp. 825-844.

W. Driehuis, 'Macro-economische voorspellingen als achtergrond van bedrijfsprognoses', in: Prognoses, tendenzen en grenzen, Nivra-geschrift no. 19, Deventer, 1977, p. 43.

H. C. Elte, R. F. Hochheimer, W. Kuipers en C. L. Worms, 'De kwaliteit van de voorspellingen van het Centraal Planbureau', Economisch-Statistische Berichten, LXIII (1978), pp. 873. 879.

J. M. Keynes, 'How to Avoid a Slump?', The Times, 12-14 januari 1937, in: T. W. Hutchison, Keynes versus the 'Keynesians' . . ', Hobart Paperback No. 11, Londen, 1977, pp. 65-77.

J. J. Klant, Spelregels voor economen (1972), Leiden, 1978, pp. 107-112, 122-125.

E. E. Leamer, Specification Searches, New York, 1978.

E. Mach, Erkenntnis und Irrtum (1905), Leipzig, 1906, pp. 192-193.

E. Malinvaud, 'Econometrics Faced with the Needs of Macro-economic Policy', Econometrica XLIX (1981), pp. 1363-1375.

A. Marshall, Principles of Economics (1890), Londen, 1961, p. 759n.

E. Nagel, 'Determination in History', in: P. Gardiner (red.), The Philosophy of History, Londen, 1974, p. 197.

P. A. Samuelson, Foundations of Economic Analysis, Cambridge (Mass.), 1948.

P. A. Samuelson, 'Lessons from the Current Economic Expansion', American Economic Review, LXIV (1974), pp. 75-77.

C. Sims, 'Macro-economics and Reality', Econometrica, XXLVIII (1980), pp. 1-48. 